\title{
Factores explicativos de los discursos y estrategias de conciliación del ámbito laboral y familiar de las mujeres inmigradas no comunitarias en España
}

\author{
Sònia Parella \\ Sarai Samper \\ Universitat Autònoma de Barcelona. Departament de Sociologia \\ 08193 Bellaterra (Barcelona). Spain \\ sonia.parella@uab.cat
}

\section{Resumen}

La dificultad de conciliar el ámbito familiar, personal y laboral es común a la mayoría de mujeres con hijos menores a cargo que participan en el mercado de trabajo. Sin embargo, los recursos con que cuentan las mujeres para hacer frente a esta dificultad son sin duda desiguales y, por consiguiente, también lo son las estrategias de conciliación a su alcance. La posición de vulnerabilidad de las familias inmigrantes no comunitarias en la estructura social permite explicar las limitaciones a la hora de diseñar estrategias de conciliación, así como el hecho de que la desigualdad de oportunidades influye no sólo en el tipo de prácticas, sino también en los discursos sobre la forma de percibir la "problemática» de la conciliación (conflicto ocupación-familia). Partiendo de una revisión teórica de la problemática y del análisis del material empírico recogido en una investigación en curso realizada en el Área Metropolitana de Barcelona, el artículo propone un marco conceptual que permita analizar los factores que intervienen en las estrategias de conciliación de las mujeres inmigradas.

Palabras clave: conciliación del ámbito laboral y familiar, conflicto ocupación-familia, estrategias, perspectiva de género, mujeres inmigrantes.

Abstract. Explanatory factors of discourses and strategies in order to conciliate work and family of non-communitary migrant women in Spain

Conciliation of work and family is a difficult enterprise for almost all women with small children willing to participate in the labour market. Nevertheless, the sort and amount of resources women have to combine paid-work and family care are very unequal and so are as well the possible strategies to conciliate work and family they can develop. The social vulnerability of migrant families in social and economic structure explains to a big extend the fewer options for some women to design conciliation strategies. This lack of equal opportunities relates not only to immigrant women's practices but to different perceptions of the conciliation "problem». We propose a model of analysis of the structural and subjective factors linked to the conciliation strategies of migrant women. The model is based on the theoretical baggage about this matter and on the empirical material collected for an ongoing research about conciliation strategies of non communitarian migrant women in the Barcelona metropolitan context.

Key words: conciliation of work and family, work-family conflict, strategies, gender perspective, migrant women. 


\section{Sumario}

\section{Introducción}

2. La conciliación ocupación-familia. Aclaraciones terminológicas

3. Los factores que influyen en la percepción del conflicto entre ocupación y familia y en las estrategias de conciliación de las mujeres inmigrantes.

El marco de análisis
4. Percepción del conflicto entre ocupación y familia y estrategias de conciliación de las mujeres inmigrantes. Algunos resultados preliminares

Conclusiones

Bibliografia

\section{Introducción}

El presente artículo se enmarca en una investigación financiada por el Instituto de la Mujer, Las mujeres inmigrantes con hijos a cargo. Detección de necesidades en el ámbito de acción de las políticas familiares y de salud (expediente número $71 / 2004)^{1}$. Estas páginas presentan los resultados de una parte de la investigación, que aborda las estrategias de conciliación de mujeres inmigrantes con responsabilidades familiares en la sociedad receptora, en el seno de familias nucleares integradas por un matrimonio e hijos, cuyos miembros residen juntos en España.

El presente artículo propone un marco teórico que permita estudiar los diferentes factores que intervienen en la percepción del «conflicto entre ocupación y familia» por parte de las mujeres inmigrantes y en las estrategias de conciliación de la vida familiar y laboral adoptadas. Nuestro objetivo es mostrar hasta qué punto los factores estructurales que tienen que ver con la posición social y económica de estas mujeres en la sociedad receptora (situación laboral, situación legal, etc.) desempeñan un papel clave a la hora de limitar los cursos alternativos de acción de estas mujeres (estrategias) en el momento de conciliar su rol laboral y su rol en la familia. En este sentido, nuestra principal hipótesis de trabajo es comprobar hasta qué punto son los factores estructurales, y no tanto las ideologías de género en las que han sido socializadas estas mujeres en sus países de origen, los que están generando estrategias de conciliación favorecedoras del repliegue hacia el rol familiar y de roles de género tradicionales.

Ante la necesidad de acotar y limitar los ámbitos de estudio, el trabajo de campo de la investigación se ha llevado a cabo en el Área Metropolitana de Barcelona (junto a Madrid, una de las principales concentraciones de mujeres

1. La investigación, en la que también participan las investigadoras Dra. Carlota Solé y Dra. Kàtia Lurbe, además de las autoras de este artículo, tiene como objetivo ofrecer, desde una perspectiva de género global e integradora, un diagnóstico de la situación de las mujeres immigrantes con responsabilidades familiares en la sociedad receptora, en términos de transformación de los roles de género dentro de la pareja, de conciliación de la vida laboral y familiar y de reconfiguración de la salud materno-infantil y psicosomática. 
extranjeras de origen extracomunitario en España) y se ha centrado en los colectivos de mujeres inmigradas originarias de Latinoamérica, Europa del Este y norte de África. Se trata de tres colectivos que son mayoritarios en número de población asentada y que permiten acceder a una gran diversidad de discursos y prácticas en cuanto a proyectos migratorios, centralidad del trabajo productivo, trayectorias laborales en el país de origen, niveles educativos y roles de género.

La investigación empírica se ha basado en la aplicación del grupo focal como técnica de recogida de información. De acuerdo con Alonso (1996), la discusión en grupo pretende, mediante la provocación de una situación comunicativa, investigar las formas de construcción significativa de la conducta del grupo o de los grupos de pertenencia y de referencia de los individuos que interactúan en el espacio micro en el que participan las personas entrevistadas. Desde una perspectiva sociológica, el grupo focal tiene como objetivo fundamental el estudio de las representaciones sociales (sistemas de normas y valores, imágenes asociadas a instituciones, colectivos u objetos, tópicos, discursos estereotipados) que surgen a partir de la confrontación discursiva de sus miembros. Nuestro trabajo de campo ha consistido en la realización de 12 grupos focales: 4 con mujeres latinoamericanas, 4 con mujeres procedentes de Europa del Este y 4 con mujeres originarias del norte de África, principalmente de origen marroquí.

\section{La conciliación ocupación-familia. Aclaraciones terminológicas}

De acuerdo con Greenhaus y Beutell (1985), definiremos el conflicto entre ocupación y familia como la consecuencia de las presiones incompatibles derivadas de los roles laborales y familiares. A lo largo de este artículo, vamos a evitar la expresión original, "conflicto entre trabajo y familia» (work-family conflict», puesto que entendemos el término "trabajo» a partir de la revisión conceptual que se ha realizado sobre los trabajos de las mujeres desde el feminismo ${ }^{2}$. Partiendo del modelo de análisis del denominado «modelo de producción y reproducción» y siguiendo la terminología del grupo de Cambridge, definimos el concepto «trabajo» a partir del planteamiento propuesto por Torns y Carrasquer $(1987,1999: 100)$. Su propuesta incluye no sólo todas las actividades orientadas a la producción de bienes y servicios en el mercado, independientemente de la forma contractual que adopten, sino también aquéllas orientadas a la reproducción biológica, social e ideológica de la fuerza de trabajo. En este sentido, distinguimos el trabajo productivo del trabajo reproductivo o doméstico-familiar.

Para que exista conflicto entre ocupación y familia, éste debe ser sentido y narrado por el sujeto, a partir de su percepción sobre la experiencia vivida en

2. Borderías, Carrasco y Alemany (1994) recogen, en una interesante selección de textos, la revisión conceptual del término "trabajo» y las nuevas teorizaciones sobre los trabajos de las mujeres en las sociedades occidentales industrializadas. 
el orden micro. Sin embargo, de acuerdo con N. Papí (2005), no es necesario que una persona sienta el conflicto para que exista de facto una incompatibilidad de situaciones en el «orden macro», a lo que denominaremos "conciliación» de ahora en adelante. En clara sintonía con los análisis críticos que, desde el feminismo, se han llevado a cabo sobre el concepto "conciliación", en este texto partimos del hecho que "conciliar» supone armonizar dos ámbitos que no se sitúan, de partida, en un mismo nivel y que presentan incompatibilidades a nivel macro. El orden establecido se basa en un sistema social y económico centrado en la producción, que no valora la reproducción de los individuos, aunque ésta última sea condición de existencia del sistema productivo y el principal garante del bienestar material y emocional de las personas.

Hombres y mujeres no se sitúan en las mismas posiciones en dicho orden social y económico desigual. De hecho, es probablemente la división del trabajo según el género el factor más importante a la hora de explicar que el mundo de la producción y el mundo de la familia se hayan considerado como áreas escasamente relacionadas, tanto a nivel académico como en las representaciones sociales. El sistema productivo ha mantenido una determinada estructura familiar que le ha permitido asegurar la necesaria oferta de fuerza de trabajo masculina, gracias al trabajo gratuito de las mujeres, que se ocupan de la reproducción de la mano de obra masculina, de los hijos e hijas y de sus padres y madres cuando alcanzan la vejez (Carrasco y otros, 2003). Esta división de tareas, que se legitima y se perpetúa a través de un proceso socializador, no sólo perfila diferencias entre hombres y mujeres; sino que también configura desigualdades de carácter estructural en todos los niveles, absolutamente necesarias para sostener la actual situación de la organización productiva (Torns, Carrasquer, 1999: 102). Los desequilibrios entre ocupación y familia que afectan a la vida cotidiana de hombres y mujeres, para ellas constituyen obligaciones y responsabilidades fuente de desigualdad y subordinación y para ellos se traducen en privilegios.

Dicha incompatibilidad no sólo se concreta a través del desigual y asimétrico reconocimiento social de ambos trabajos — a saber, productivo y reproductivo- , sino también desde la lógica del espacio y el tiempo. La socióloga italiana L. Balbo (1978) describe esta situación con el término «doble presencia» y lo distingue de la "doble jornada", dado que pretende reflejar no la superposición de dos jornadas de trabajo distintas y separables; sino una doble carga de trabajo desarrollada en un mismo espacio, tiempo y jornada, con lo que ello supone de volumen e intensidad de trabajo material y de condicionamiento de las actitudes y valores de las mujeres ante la vida familiar, laboral y personal.

Partiendo de dicha incompatibilidad de partida entre ambos trabajos, la conciliación no es más que un intento de armonizar ambas esferas. En este sentido, siempre han existido estrategias de conciliación de la ocupación y la familia. La división sexual del trabajo es una de ellas. La gran mayoría de las mujeres asume en exclusiva las responsabilidades del trabajo doméstico y familiar, mientras la gran mayoría de los hombres construye su proyecto central 
de vida sobre el trabajo de la producción (Brullet, 2000). Ciertamente, el modelo de familia denominado «male breadwinner» (hombre «cabeza de familia» y mujer «ama de casa») ha ido perdiendo fuerza como pauta de referencia en nuestra cultura occidental con la generalización de la incorporación de la mujer en el mercado de trabajo. Sin embargo, lejos de haber reducido su función de cuidadora, gestora y ejecutora de las tareas del hogar, la "nueva» conciliación ha supuesto para las mujeres ejercer de «variable de ajuste» de los tiempos de los demás y sumar cargas y presencias («doble presencia»), mientras el hombre ha mantenido su rol unipresencial en la esfera productiva prácticamente intacto. Sigue siendo, pues, a las mujeres a quien corresponde en buena medida resolver los conflictos vinculados a la «conciliación» (Carrasco y otros, 2003) ${ }^{3}$.

Por consiguiente, de acuerdo con los análisis críticos sobre la conciliación desde una perspectiva de género (Brullet, 2000; Torns, 2004; Carrasquer, 2005), plantear políticas a favor de la conciliación entre ocupación y familia no siempre supondrá la disminución de las desigualdades de género, sino todo lo contrario. Porque, en función de cómo se entienda la conciliación y de cómo se le dé respuesta, lo que puede suceder es que se refuerce el patriarcado (y, por consiguiente, las desigualdades de género) y se faciliten estrategias que simplemente hagan más «soportable» la «doble presencia» con la que conviven las mujeres, en términos de calidad de vida, sin modificar el tradicional reparto de funciones sociales entre hombres y mujeres e incidiendo de forma negativa en la igualdad de oportunidades. Sólo aquellas estrategias de conciliación que tengan como objetivo avanzar hacia una progresiva, equitativa y flexible ocupación simétrica de los espacios y de los tiempos de la vida cotidiana entre hombres y mujeres contribuirán a promover la equidad entre géneros (Brullet, 2000).

Con este cometido, el presente estudio se ocupa tanto de las interferencias que puede producir el ámbito laboral sobre la familia, como las que el rol familiar puede provocar en la ocupación. El impacto de dichas interferencias es estudiado en términos de percepción de "conflicto entre ocupación y familia" por parte de las mujeres inmigrantes y en las estrategias de conciliación que adoptan. Por estrategias, de acuerdo con L. Garrido y E. Gil Calvo (1993), entendemos la selección de cursos alternativos de acción (recursos tácticos) para producir resultados futuros (objetivos estratégicos) en situaciones de incertidumbre. Esta concepción del comportamiento estratégico aplicada a nuestro objeto de estudio permite definir las estrategias de conciliación como el margen disponible de las personas a la hora de optimizar los recursos con el fin

3. Aunque también es cierto que los hombres, sobre todo entre las generaciones más jóvenes con mayor nivel educativo, están aumentando paulatinamente su implicación en las tareas reproductivas y que la mujer con un empleo remunerado opta de forma creciente por externalizarlas, aunque sin dejar de supervisarlas. Ciertamente, la responsabilidad sigue recayendo en ella, pero sus estrategias pasan cada vez más por recurrir al mercado y/o por involucrar cada vez más al hombre (Tobío, 2001). 
de adaptarse a las constricciones del medio social en términos de escoger el rol familiar y el rol laboral y de hacerlos compatibles.

\section{Los factores que influyen en la percepción del conflicto entre ocupación y familia y en las estrategias de conciliación de las mujeres inmigrantes. El marco de análisis}

Las mujeres de origen inmigrante comparten con el resto de madres trabajadoras la "suma de presencias» y la dificultad de llevarlas a cabo en el contexto de un sistema social y económico centrado en la producción y de un Estado de bienestar, el español, con un escaso e insuficiente desarrollo de servicios para las familias. Sin embargo, es evidente que la vivencia de la "doble presencia», común a la mayoría de mujeres, difiere según cual sea su origen social y su posición en la estructura social ${ }^{4}$.

Para el caso específico de las mujeres inmigrantes, nuestra hipótesis de partida es que la triple condición de «mujeres», «inmigrantes» y de «clase trabajadora» las sitúa en una posición "de riesgo" en la sociedad receptora; posición que explica la existencia de obstáculos específicos a la hora de gestionar su participación cotidiana en el empleo y la familia y, en definitiva, de vivir la experiencia de la conciliación de su vida familiar y laboral. A la hora de acercarnos a los determinantes de las estrategias de conciliación de las mujeres inmigrantes (véase figura 1), distinguimos dos tipos de factores que suelen considerarse influyentes en el conflicto entre ocupación y familia: los derivados del rol laboral y los que tienen que ver con el rol familiar.

En cuanto a los factores influyentes propios de la esfera productiva, identificamos, en primer lugar, la estructura de oportunidades laborales para las mujeres inmigradas. Por un lado, el estatus de las mujeres inmigrantes se ve afectado por las restricciones de una estructura ocupacional sexualmente segregada, en la que las mujeres obtienen salarios más bajos, menor estabilidad y menos oportunidades de promoción que sus homólogos masculinos, independientemente de su capacitación. En este sentido, los inconvenientes que entraña el hecho de ser inmigrante implica que la trabajadora inmigrante, en comparación con la mujer autóctona, se halle en los estratos más bajos de la estructura ocupacional, cubriendo los huecos laborales peor pagados, con menos prestigio social y eludibles por las trabajadoras autóctonas, por ser emble-

4. A modo de ejemplo, las madres de clase trabajadora, con posiciones laborales débiles y precarias y con escaso poder adquisitivo, padecen todas las consecuencias de no poder compaginar los distintos tiempos y trabajos en su vida cotidiana, en un contexto de ausencia de servicios a la vida diaria y sin recursos económicos propios para poder «inventar» estrategias que no penalicen su trabajo remunerado o la atención de sus hijos. En cambio, para las madres trabajadoras con mayor poder adquisitivo, el reto de la "doble presencia» es sin duda más soportable y el abanico de estrategias, más amplio, por cuanto tienen la opción de mercantilizar o externalizar parte del trabajo doméstico y familiar. En este sentido, muchas parejas con recursos eliminan el conflicto del reparto de tareas reproductivas a través de contratar a una trabajadora (Brullet y Parella, 2005). 
máticos de la discriminación de género. Nos estamos refiriendo, principalmente, a actividades como el servicio doméstico o la prostitución, sin olvidar otros servicios poco cualificados dentro de los sectores de la hostelería o el comercio (Parella, 2003).

Estos nichos laborales a los que tiene acceso la mujer inmigrante se caracterizan por la precariedad, el desprestigio social, los bajos salarios, la desregulación y la invisibilidad (Colectivo Ioé, 2001; Parella, 2003). La situación de vulnerabilidad laboral de la mujer inmigrante es máxima cuando su situación legal es irregular o cuando sólo cuenta con autorización de residencia sin permiso de trabajo, por cuanto sólo va a poder tener acceso a una actividad remunerada dentro de la economía sumergida. Es evidente que las condiciones laborales, por su propia naturaleza, influyen directamente en las facilidades o dificultades para que la conciliación sea viable (Chinchilla, Poelmans, 2004). Pero, además, dichas condiciones también inciden a la hora de valorar hasta qué punto optar por un trabajo remunerado compensa o no a la mujer inmigrante (salarios por debajo del coste de los servicios de guardería, inconsistencia de estatus, etc.).

En lo que concierne al rol laboral, otro factor determinante de la percepción del conflicto entre ocupación y familia es la centralidad del empleo para las mujeres. De ese modo, el hecho de desarrollar un trabajo remunerado puede responder a una orientación meramente instrumental, que sólo persigue cubrir necesidades de tipo material — que, en caso de ser cubiertas, implicarían el cese del vínculo laboral—; o bien puede ser el resultado de una orientación de carácter expresivo que, más allá de los ingresos, concibe el empleo como instrumento que facilita el desarrollo personal, aumenta la autoestima, la autonomía, el autocontrol, etc. En dicha centralidad influye el proyecto migratorio de la mujer inmigrada, la situación económica del grupo familiar (hasta qué punto sus aportaciones derivadas del trabajo remunerado son consideradas como una "ayuda», etc.), su nivel educativo y su trayectoria laboral previa en el país de origen.

Por otra parte, en nuestro marco de análisis identificamos los factores influyentes que tienen que ver con el rol familiar. El número de hijos a cargo y la edad de los mismos condiciona sin duda el volumen y la intensidad de necesidades derivadas de la esfera reproductiva y la disponibilidad de tiempo y de flexibilidad a la hora de conciliar. El tipo de proyecto migratorio, distinguiendo aquí entre mujeres que han protagonizado migraciones autónomas de carácter económico - harto frecuente entre las latinoamericanas y las procedentes de países de Europa del Este- - y las que han llegado a través de la reagrupación familiar y no han tenido una trayectoria laboral previa en su país de origen — patrón habitual entre buena parte de las participantes de origen marroquí en los grupos focales-, condiciona la importancia concedida a cada uno de los distintos roles en la vida de estas mujeres.

Sin lugar a dudas, los autoesquemas de género constituyen un determinante clave dentro del rol familiar. De acuerdo con la teoría del esquema de género de Bem (1981), el autoconcepto de género se desarrolla en función del 
esquema de género del individuo, a partir de las pautas de actitudes y comportamientos que marcan los roles asociados a hombres y a mujeres. De la aplicación de dicho esquema a las actitudes y comportamientos de las mujeres, podemos identificar, por un lado, aquellas que, tras haber interiorizado y aceptado las normas típicas de la sociedad como masculinas o femeninas, actúan sobre la base del estatus que se les asigna a partir del estándar o «normas sociales» del rol de «mujer» asumido. Las normas sociales son expectativas ampliamente compartidas referentes a la conducta adecuada de las personas que ocupan roles o estatus dados, o se encuentran en escenarios o situaciones específicas (Saltzman, 1992). Por otro lado, otras mujeres sienten una limitación al tener que cumplir con los comportamientos que definen su rol de género asociado a su condición de mujer y disponen de una mayor flexibilidad y variedad conductual (Martínez y otros, 2002). De ese modo, distinguimos entre las mujeres con autoesquema de género tradicional, sujetas al modelo normativo de mujer "ama de casa», cuidadora y esposa amantísima, de las "no tradicionales», mucho más independientes respecto de los roles de género asignados socialmente.

Llegados a este punto, debemos matizar que, aunque el autoesquema de género no sea «tradicional», ello no implica necesariamente que una mujer con un empleo remunerado actúe de forma independiente a los roles de género. El autoesquema de género de una mujer occidental de clase media, por ejemplo, puede que haya superado ya la rigidez del tradicional —en el sentido de tratarse de mujeres que no quieren renunciar a una carrera profesional propia-, pero no por ello actúan al margen de los roles tipificados según el género en sus estrategias: la «doble presencia» femenina desde la asunción de la gestión y ejecución de buena parte del trabajo reproductivo - a diferencia de los hombres—; o bien la «doble presencia» a partir de la externalización de parte de este trabajo reproductivo, aunque sin dejar ellas de supervisarlo y de asumirlo como responsabilidad y «algo propio». En nuestro estudio, a la hora de analizar los autoesquemas de género, definimos un autoesquema como «tradicional» en la medida en que estas mujeres tengan interiorizado que son ellas - y no ellos - las que tienen que hacerse cargo del conjunto de responsabilidades asociadas con el trabajo reproductivo, con independencia de que tengan o no una actividad remunerada.

Por último, en las estrategias de conciliación de las mujeres inmigrantes, deben tenerse en cuenta también otro tipo de recursos que van más allá de la dimensión estrictamente laboral y familiar. Sin lugar a dudas, las madres trabajadoras autóctonas están encontrando en la generación precedente, en las denominadas «abuelas-madre», la ayuda y la solidaridad sin las cuales muchas no podrían mantener sus empleos con la llegada de los hijos — sobre todo las mujeres con menos recursos que no pueden costearse servicios privados(Tobío, 2001). Sin embargo, el debilitamiento de las redes familiares es una de las pérdidas que experimentan las mujeres inmigrantes como consecuencia de haber emigrado. Para estas madres, una de las mayores dificultades que experimentan es el tener que adaptarse a una sociedad mucho más individua- 
lizada que la de origen, donde las solidaridades familiares —especialmente entre las mujeres de la familia - eran más habituales. El recurso a las redes familiares se desvanece en la sociedad receptora, ello se explica no sólo porque en muchos casos los miembros de la familia extensa permanecen en el país de origen y la mujer inmigrante está sola y no puede contar con sus seres queridos; sino también porque los ritmos de trabajo y la falta de tiempo libre que tienen los y las inmigrantes aquí, dificulta en muchos casos poder mantener el mismo tipo de vínculo que tenían en la sociedad de origen (Brullet y Parella, 2005).

Finalmente, nuestro marco teórico incorpora otro tipo de recursos también esenciales a la hora de gestionar el conflicto entre ocupación y familia: las prestaciones sociales del Estado de bienestar en favor de la conciliación. El Estado de bienestar español, caracterizado por su escaso desarrollo de un sistema universal de derechos sociales y por la insuficiencia de servicios próximos y gratuitos para el conjunto de la ciudadanía (plazas públicas en guarderías, asistencia a las personas dependientes, etc.), no sólo dificulta la conciliación de la vida laboral y personal, sino que acentúa el conflicto entre ocupación y familia para las mujeres que, a diferencia de lo que ocurre en otros regímenes de bienestar, deben de gestionar y asumir un mayor volumen de trabajo. Dicho panorama tiene una diferente repercusión en función del poder adquisitivo de las familias. Para las mujeres inmigrantes, su frágil y precaria posición socioeconómica dificulta en la mayoría de casos su acceso a los servicios privados. Por consiguiente, no tener acceso a servicios públicos y gratuitos puede suponer en muchos casos tener que renunciar a la vida laboral — siempre que esta opción sea posible—; o bien tener que adaptar al máximo su participación laboral a las necesidades reproductivas, asumiendo la centralidad de la ocupación del marido y concibiendo la propia como "complementaria», aunque a la vez imprescindible — por cuanto los ingresos del marido, por sí solos, no son suficientes para asegurar la solvencia económica del grupo familiar- 5 .

5. Cuando se trata de mujeres con hijos a cargo que encabezan situaciones de monoparentalidad, la no-accesibilidad a los servicios facilitadores de la conciliación puede conllevar fuertes situaciones de estrés para unas mujeres que cuentan sólo con sus ingresos para la supervivencia del grupo familiar. En estos casos, se dan estrategias extremas, en los términos de Tobío (2001), tales como desatender a los hijos mientras la madre trabaja. Las dificultades de conciliación también explican el hecho de que muchas madres emigren dejando a sus hijos en el país de origen a cargo de otras personas, generalmente sus abuelas. Es lo que se conoce como «maternidad transnacional». Asimismo, también es harto habitual que, cuando los hijos nacen aquí y las madres carecen de soporte para poder compaginar su trabajo remunerado con el cuidado del bebé, se vean obligadas a tomar la difícil decisión de desprenderse de su hijo y mandarlo a su país para que se ocupe de él la familia que permanece allí (Brullet y Parella, en prensa). 


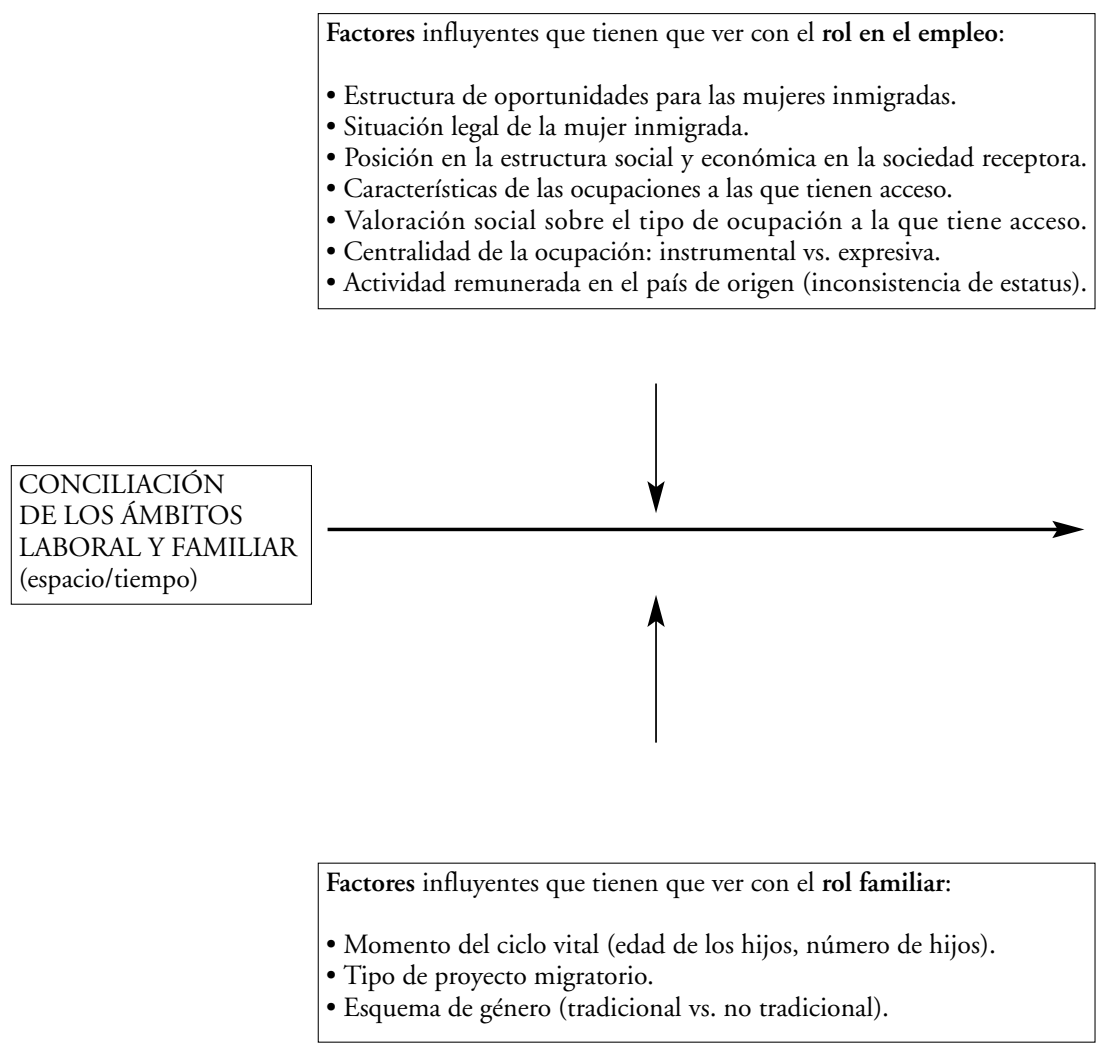

\section{REDES FAMILIARES \\ Y RECURSOS \\ COMUNITARIOS}

TIPOS

DE ESTRATEGIAS:

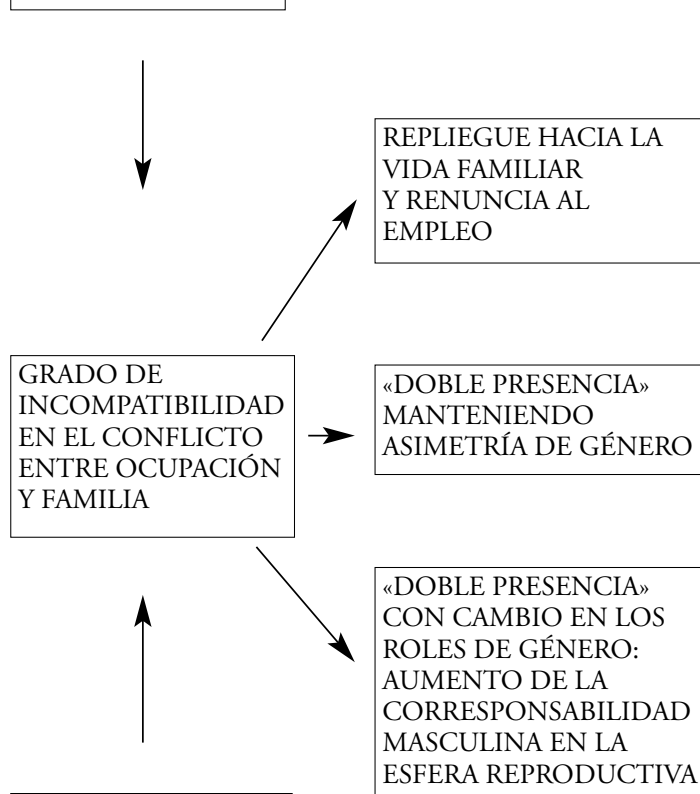

\section{OFERTA Y}

ACCESIBILIDAD DE

LOS SERVICIOS

SOCIALES

Figura 1. Factores que influyen en las estrategias de conciliación del ámbito laboral y familiar para las mujeres inmigradas. 


\section{Percepción del conflicto entre ocupación y familia y estrategias de conciliación de las mujeres inmigrantes. Algunos resultados preliminares}

Este apartado pretende ofrecer un análisis preliminar de los resultados de los grupos focales, con la principal finalidad de explorar la potencialidad explicativa del marco de análisis que aquí se propone (ver la figura 1). No se trata, por tanto, de un análisis exhaustivo, sino de una recopilación de las principales líneas de consenso observadas en el análisis de nuestro trabajo de campo.

En lo que concierne a la percepción del conflicto entre ocupación y familia, las participantes no cuestionan en ningún momento que sea a ellas a quien corresponde responsabilizarse del trabajo doméstico familiar. La influencia de este autoesquema de género tradicional se traduce en todo tipo de estrategias de conciliación que pasan por adaptar el trabajo remunerado a los requerimientos familiares y raramente se reclaman estrategias que supongan un avance hacia la corresponsabilidad entre el marido y la mujer. El hecho de que las mujeres no reclamen renuncias a sus cónyuges en el terreno laboral para facilitar la conciliación, se justifica tanto por motivos pragmáticos (los hombres perciben salarios más elevados, ellos llegan más cansados porque tienen jornadas más largas y más duras), como por motivos morales o ideológicos (autoesquema de género):

Ahora el problema es que están de vacaciones y me tengo que quedar con los brazos cruzados con los dos. Y si van a un casal me cuesta unos $150 €$. Pues me quedo con los hijos en la casa. Mi marido no puede ayudarme, porque dice que lo que a mí me van a pagar está muy por debajo de lo que él gana. (Gabriela, 30 años, latinoamericana, GF7)

Entonces yo lo empiezo a valorar, gano tanto y la cuestión de mis hijos se me está yendo de las manos. Es cuestión de valorar y yo valoré. Un trabajo, de acuerdo, pero de acuerdo a como yo los pueda educar a ellos. Eso sí, el papá «vaya a trabajar todo el día que ya de mí depende». (Carina, 44 años, latinoamericana, GF2)

En cuanto a las actitudes de estas mujeres hacia el trabajo remunerado, las que ya tenían un empleo remunerado en sus países de origen y que han emigrado por razones principalmente laborales - éste es el caso sobre todo de las mujeres latinoamericanas - , ven incrementar su rol productivo dentro de sus familias a consecuencia del diferencial salarial que obtienen con la inmigración, incluso teniendo que realizar en el país receptor una actividad desprestigiada y no acorde con su nivel educativo (inconsistencia de estatus). Su orientación hacia el trabajo remunerado es, ante todo, instrumental. Su condición de migrantes económicas convierte en un imperativo la participación laboral de estas madres.

Por ejemplo, mis padres son dos personas inválidas, mi madre no camina, tengo más hermanos allí, pero... Entre que tienen muchos hijos, uno tiene 
cinco, la otra tiene cuatro, y entonces no tienen para darle a nadie, digo yo, más que para comer. Entonces, la que mira por mis padres soy yo, o sea, que si yo no mando dinero, mis padres no comen, así de claro. Y el sueldo que gana mi marido, vale, me sirve para..., podría yo estar en la casa, pero no, no puedo, no puedo porque para mí es una obligación. (Mari Carmen, 27 años, latinoamericana, GF8)

Sin lugar a dudas, el proceso de inserción laboral de las mujeres en la sociedad receptora les proporciona tanto mejoría económica, como un mayor grado de autonomía en la toma de decisiones dentro del núcleo familiar en relación con su situación en su país de origen, máxime cuando se trata de mujeres que no habían contado con un empleo con anterioridad. Sin embargo, de acuerdo con M. Alicea (1997), no debemos olvidar sus condiciones sociales de invisibilidad como mujeres e inmigrantes, así como la subordinación que experimentan en el mercado de trabajo; un mercado que las relega a los estratos más bajos de la estructura ocupacional. Ello permite entender la ambigüedad y la ambivalencia de su discurso, por cuanto se sienten orgullosas de trabajar fuera del hogar y sostener económicamente a sus hijos; al tiempo que sus fuentes de satisfacción no necesariamente proceden de una actividad remunerada desprestigiada, desregularizada y emblemática de la discriminación de género. Ello explicaría que muchas de ellas sigan subordinadas a la identidad primaria como madres y perpetúen el statu quo de asimetría en las relaciones de género dentro del grupo doméstico (Pessar, 1984; Pedone, 2006: 195). De ese modo, y especialmente en el caso de las mujeres reagrupadas, la familia se convierte en un refugio de la discriminación social y laboral a la que se enfrentan en la sociedad de acogida (Pedone, 2006: 196).

[...] a ver, de aprender en el trabajo nada, porque hago lo mismo que hacía en Bolivia, limpiar en mi casa, con la diferencia que ahora lo hago con gente extraña. Pero pienso que si yo volviera para atrás y me hubieran dicho cómo es aquí, yo no venía ni aunque me regalaran el billete de ida y de vuelta y me regalaran una casa. Porque pienso que, como bien dice A., uno viene por sus necesidades económicas, pero a veces el dinero no lo es todo y yo me pongo a poner como ella dice en una balanza y yo prefiero volver a mi tierra y dormir bajo un árbol tapada con una carpa, con mis padres, con mi familia, tener el amor de mi familia únicamente y vivir y trabajar y tener para comer y para que los niños vayan al «cole» y tal, creo que me bastaría y me sobraría. Porque aquí, lamentablemente, ganamos más dinero, podemos mandar a nuestros padres, podemos ayudar a quien queremos, pero estamos solos. (Berta, 34 años, latinoamericana, GF8)

Las asimetrías de género dentro del grupo doméstico se ponen de manifiesto desde el momento que la mujer concibe la conciliación como algo que sólo le atañe a ella en calidad de esposa y madre. Las estrategias de conciliación que se diseñan desde esta percepción del conflicto entre familia y empleo consisten principalmente en adaptar y subyugar su rol laboral a los requeri- 
mientos familiares. Reducir la actividad laboral es la estrategia más habitual de las mujeres inmigrantes cuyo esposo desempeña una actividad remunerada y convive con ellas en la sociedad receptora. Para estas mujeres, las opciones laborales más "conciliadoras» se circunscriben mayormente a empleos por horas - por ejemplo, en el servicio doméstico-, que puedan realizar durante el horario en que sus hijos están atendidos en la escuela, empleos remunerados nocturnos o de fines de semana (residencias de ancianos, fábricas), empleos informales u ocasionales (que les permitan trabajar cuando sus hijos se ponen enfermos o tienen vacaciones), o que puedan realizarse desde casa (ventas por catálogo, costura, etc.). Este tipo de empleos, además, permiten a muchas mujeres inmigrantes poder llevar a sus hijos al lugar de trabajo cuando no tienen con quién dejarlos — si están enfermos o en periodos vacacionales, por ejemplo-, como una estrategia de conciliación:

Yo empiezo a la una y media, salgo de casa a la 1 y 25 llego cinco minutos tarde o 10 minutos tarde, está cerca de mi casa, y a las 4 y media sale mi hijo y como no quiere que vaya nadie a por él, quiere que vaya yo, a las 4 pido una hora voy desde Joan Prim, voy al colegio, lo recojo, vuelvo al trabajo con él porque me queda trabajo, está en mi trabajo [...] el horario que hace falta se queda allí conmigo, se queda pintando o me ayuda, o pintamos o se viene conmigo en la barra y le voy diciendo las botellas que me tiene que traer y yo las pongo... Llegamos a las seis y media o a las siete a casa, a ducharle, a darle de cenar y la camita. Y yo entro en la cama y nada más cerrar los ojos ya estoy durmiendo, estoy agotada. (Nica, 21 años, europea del Este, GF3)

Pero dichas estrategias de conciliación presentan claras contrapartidas, por cuanto las ventajas que pueden ofrecer este tipo de empleos en términos de "flexibilidad horaria», se ven oscurecidas por la informalidad bajo la cual se suelen ejercer, la precariedad, los bajos salarios y la falta de derechos laborales. Ello refuerza la inestabilidad laboral de estas mujeres, dificulta la movilidad laboral fuera de estos "nichos laborales» y contribuye a acentuar la dependencia económica y simbólica hacia el cónyuge, por cuanto sus aportaciones derivadas del trabajo remunerado son consideradas como "una ayuda» y, además, incierta. Se trata de estrategias que en ningún caso contribuyen a un cambio de los roles de género que permita avanzar hacia una corresponsabilidad masculina en el ámbito doméstico y a una mayor equidad entre géneros.

[...] de trabajar por horas está bien, hasta cierto punto. Porque yo cuando tuve el problema de que estuve ingresada y que no trabajaba me las vi fatal y gracias a la señora L. y a su madre mis hijos tenían para comer, porque mi esposo gana cuatro euros la hora y, trabaje los días que trabaje, gana 700 euros al mes, entonces, mucho mucho no podemos hacer. Y pienso yo ahora, personalmente, estoy buscando una empresa para trabajar donde que si bien mañana me tuerzo un pie, pueda tener baja médica y cobrar la baja médica porque ahora no podemos. Es más, el día que estuve aquí en el hospital, me dijo el médico: «te 
hago la baja médica porque necesitas baja médica quince días», y yo le dije: "mire doctor, es que soy autónoma», y me dice "ay bueno, pues si trabajas cinco horas, trabaja sólo dos!», y se solucionan así las cosas. Y en ese sentido, creo que es un poco no tan bueno trabajar por horas. (Berta, 34 años, latinoamericana, GF8)

Aspirar a empleos más formalizados y de jornada completa — donde la presencia de los hijos no estaría permitida - , requiere contar con la plena disponibilidad de algún familiar cercano, como pueda ser una madre o una hermana; o bien una cantidad de recursos económicos que permitan costear servicios privados - en ausencia de servicios públicos gratuitos-, que generalmente no están al alcance de las familias inmigrantes. El recurso a los servicios privados — tales como las guarderías o los «canguros»— es poco utilizado por parte de las mujeres inmigrantes con hijos a su cargo, a tenor de su elevado coste. Aún así, determinados servicios, como los comedores escolares, o los servicios de "acogida» en las escuelas — generalmente antes y después de iniciar el horario lectivo-, aún siendo de pago, se convierten en indispensables para poder mantener un empleo. En este sentido, la demanda de más plazas en guarderías públicas, con horarios más extensivos, así como becas de comedor y espacios lúdicos para los niños fuera de horario escolar y en periodos vacacionales, ha sido una constante en todos los grupos focales. De la accesibilidad a estos servicios dependen en muchos casos las opciones laborales que finalmente tengan estas madres:

En mi caso, este año pedí la beca para los niños en la guardería y me dieron la beca completa, con comedor y todo. Pero para este año no lo sé, porque como el niño ya va al P3, lo puse en una escuela pública y pedí la beca para el comedor. Le expliqué lo mismo que no puedo trabajar por eso y que si él se queda a comer yo puedo conseguir un trabajo hasta la 4, cuando sale. (Gabriela, 30 años, latinoamericana, GF7)

En los casos de mujeres reagrupadas por su cónyuge (este es el caso de algunas mujeres marroquíes), si no cuentan con una trayectoria laboral previa en el país de origen y si el marido percibe suficientes ingresos como para convertir en «innecesario" el trabajo remunerado "complementario» de la mujer, las funciones reproductivas de las mujeres quedan reforzadas y a veces revestidas de una ideología de género tradicional.

[...] mira, la verdad, que yo trabajar... Si mi marido tiene un sueldo bueno, yo no pienso trabajar, mejor para mí quedarme con mis hijos más tiempo, quedar conmigo mejor. No te digo que no quiero trabajar, pero yo prefiero estar con mis hijos, no puedo dejarlos. Si mi marido gana bien no voy a salir a trabajar, porque mis hijos para mí quedar conmigo. Porque miro y pasan muchas cosas ahí, mujeres que trabajan y pasan muchos problemas con los niños y no quiero buscar problemas con mis hijos, ni nada. No, no quiero por ejemplo que mis hijos llegan tarde a la casa, no quiero entrar a mi hijo en la 
guardería, mejor que primer tres años esté conmigo en la casa, cuidarlo, mirar cómo está. (Iba, 27 años, marroquí, GF5)

Sin embargo, la estrategia de estas mujeres de optar por centrarse únicamente en su vida familiar no responde únicamente a su «autoesquema de género tradicional». Por lo general, se trata de matrimonios en los que el propio varón ha modificado sus actitudes hacia la rígida división sexual del trabajo y la prohibición del trabajo remunerado de la mujer. Los «autoesquemas de género» cambian y se concibe la familia del "doble ingreso» como algo necesario. Las propias mujeres se sienten frustradas y socialmente aisladas por la renuncia al empleo y la justifican por razones que tienen menos que ver con la ideología de género y sí mucho en cambio con factores estructurales de la sociedad receptora: los bajos salarios que estas mujeres van a percibir en los nichos laborales a los que tienen acceso están por debajo del coste derivado de tener que sufragar servicios privados, sobre todo de guardería, en ausencia de redes familiares - dicho coste se incrementa a medida que aumenta el número de hijos a cargo- - Esta situación se intensifica para las mujeres que carecen de permiso de trabajo, por cuanto sus opciones laborales se restringen a la economía sumergida - circunstancia harto habitual entre las mujeres marroquíes que han sido reagrupadas y que no cuentan con permiso de trabajo- - Ante este desalentador panorama, muchas veces el trabajo remunerado simplemente es una estrategia que no compensa en términos de coste-beneficio y la mujer opta por permanecer en el hogar.

Sí, lo de dejarlo en la escuela, pagar la guardería y el coste de la comida, no sé como será en los otros colegios pero en mi colegio son 5 euros diarios de la comida más la guardería. Si una gana 600 , por ejemplo de camarera como trabaja ella, si ganas 600 son 350 que se van en la escuela, no es rentable. (Victoria, 29 años, latinoamericana, GF2)

[...] la respuesta, realmente, es que las mujeres marroquíes aquí no trabajan porque realmente el sueldo no es suficiente, ¿sabes? Como mucho son 600 euros. (Samira, 41 años, marroquí, GF6)

Las redes familiares, con las abuelas en primer lugar, son sin duda el mayor apoyo para las madres inmigrantes que quieren o tienen que trabajar, en los casos excepcionales en que dichas abuelas residen aquí. Muchas veces, el momento del parto en el país de destino se convierte en el momento idóneo para traer «temporalmente» a los abuelos o a la abuela, dado que la madre va a pasar por un periodo de convalecencia. A la larga, esta primera visita puede convertirse en una reagrupación duradera. Si bien es cierto que, con la inmigración, muchas veces se deja de disponer del soporte de los familiares que quedaron en el país de origen, son ya muchas las mujeres inmigrantes que, gracias a los procesos de reagrupación, empiezan a contar con sus madres o hermanas para el cuidado de los hijos. El papel de las tías, cuñadas, primas, etc., también muy presentes en el país de destino, no parece cobrar, en cambio, un peso importante en 
las estrategias de conciliación. Ello es así probablemente porque los ritmos de trabajo y la falta de tiempo libre que tienen los inmigrantes y las inmigrantes en la sociedad receptora, dificulta en muchos casos poder mantener el mismo tipo de vínculo que mantenían en la sociedad de origen (Brullet y Parella, en prensa):

Me hubiera sido imposible trabajar si no estuviera aquí a mi madre. Con los sueldos que he ganado siempre, no podía pagar la guardería y no podía dejar a mis hijos. Yo he trabajado porque mi madre está aquí. (Souad, 30 años, marroquí, GF1)

Ante la debilidad de las redes familiares, las redes de soporte integradas por otras mujeres inmigrantes adquieren importancia. La ausencia de redes familiares muchas veces se suple con redes informales de apoyo, integradas por relaciones de amistad, o simplemente por mujeres connacionales a las que se ha conocido en el barrio, en la escuela de sus hijos o incluso durante el viaje hacia España (Brullet y Parella, 2005). Pero raramente estas redes informales suplen el papel de apoyo diario y continuado que ofrecen las redes familiares: se trata más bien de redes de apoyo moral reservados para momentos de especial necesidad:

Yo tengo una amiga, ésta de aquí de España que vive en el primero y ahora sale con los niños, bueno, mañana acaba la escuela, pero en junio ha empezado la jornada intensiva y sale a la una y esa amiga mía me lo lleva, le da de comer y todo. (Mara, 38 años, europea del Este, GF3)

\section{Conclusiones}

Los problemas de conciliación de la vida familiar y laboral, propios de todas las madres trabajadoras, adquieren para las mujeres inmigrantes con hijos a cargo una dimensión especial, por su triple condición de mujeres, de clase trabajadora e inmigrantes — no ciudadanas-, en un contexto de recepción que no favorece estrategias de conciliación que permitan reducir las desigualdades de género. Ciertamente, con independencia de la diversidad de proyectos migratorios, se trata generalmente de mujeres que suscriben un imaginario colectivo que les atribuye en exclusiva las responsabilidades familiares y que está fuertemente arraigado en los países de origen. Por lo general, sigue siendo el esposo quien ejerce de breadwinner — cabeza de familia- y son ellas las principales responsables del trabajo doméstico y familiar.

Sin embargo, dicho autoesquema de género tradicional, aunque determinante, por sí mismo no permite entender la percepción del conflicto entre ocupación y familia para estas mujeres una vez en la sociedad receptora, ni tampoco sus estrategias de conciliación. Para ello, es menester incorporar otro tipo de factores influyentes en nuestro marco analítico, que tienen que ver con la socie- 
dad receptora y con la condición de inmigrantes de estas familias y en cómo ésta condiciona el acceso a los recursos.

Se trata de mujeres con una limitada estructura de oportunidades en el mercado de trabajo de la sociedad receptora, restringida a «trabajos de mujeres» desregularizados, precarizados y con bajos salarios. Además, muchas veces carecen de redes familiares en la sociedad receptora, en un contexto de insuficiente desarrollo de los servicios familiares facilitadores de la conciliación. Ante tal panorama, la centralidad de la ocupación es sobre todo instrumental, orientada a la mera percepción de ingresos y a la contribución a la mejora de la economía del grupo familiar, tanto en el país de destino como también en el país de origen - a través del envío de remesas-. Especialmente cuando se trata de mujeres con estudios y con una trayectoria laboral previa cualificada en sus países de origen, la «inconsistencia de estatus» impide que, una vez aquí, valoren su empleo en términos de carrera profesional y de satisfacción personal.

El repliegue hacia el rol familiar contribuye a impulsar estrategias de conciliación que persiguen lidiar con la «doble presencia» desde la prioridad del rol familiar y desde actitudes de género tradicionales, y no tanto desde las responsabilidades compartidas entre hombres y mujeres. De todo ello se desprende que el autoesquema de género actúa no sólo como un factor influyente de las actitudes y prácticas de estas mujeres; sino que también puede ser considerado, en cierto modo, una variable dependiente, por cuanto éste cambia en función del grado de satisfacción y reconocimiento que una mujer encuentra en el ámbito familiar y en el laboral una vez en la sociedad receptora. En este sentido, una experiencia laboral frustrante, como la que muchas veces encuentran las mujeres a través de la inmigración, refuerza un autoesquema de género tradicional en el que la mujer se entrega a la reproducción del grupo familiar.

Asimismo, por cuanto los autoesquemas de género no son ni los principales ni los únicos determinantes de los roles laborales de las mujeres inmigrantes - al interactuar de forma permanente con la estructura socioeconómica que determina las oportunidades de las mujeres inmigrantes-, nuestros resultados obligan a repensar no sólo la necesidad de ampliar y mejorar las oportunidades laborales de estas mujeres y aprovechar su capital humano, sino de diseñar políticas de conciliación que faciliten su incorporación laboral teniendo en cuenta las especificidades de este colectivo en el acceso a los recursos: escaso poder adquisitivo y ausencia de redes familiares, etc. Se trata de circunstancias que tienen que ver con su posición en la estructura social y económica de la sociedad receptora, sin base cultural; por otra parte comunes a muchas mujeres autóctonas de clase trabajadora, que se encuentran en parecidas situaciones de vulnerabilidad. De no ser así, las estrategias privadas de conciliación más racionales para estas mujeres van a seguir siendo, o bien renunciar al empleo y ocuparse de la familia a tiempo completo - a pesar de vivir en muchos casos con frustración la ausencia de empleo-, o bien optar por supeditar la actividad laboral a las necesidades familiares, salvo en los casos en que la mujer es la única sustentadora económica de los hijos (situaciones de monoparenta- 
lidad). En ambos casos, aunque con distinta intensidad, se refuerza - o cuanto menos se mantiene- la dependencia económica hacia el cónyuge masculino y los roles de género tradicionales.

Ambos tipos de estrategias de conciliación (renunciar al empleo o supeditar la actividad laboral a las necesidades familiares) tienen efectos negativos, no sólo en términos de desigualdad de género y de asimetrías de poder dentro y fuera del núcleo familiar. Los obstáculos al modelo de familia de «dos salarios" suponen, para estas familias, graves problemas económicos en un momento de su ciclo vital en el que los gastos son muy elevados. Además dichas estrategias comportan un aumento del riesgo, por cuanto los vínculos laborales de los trabajadores masculinos de origen inmigrante muchas veces también son precarios. El reforzamiento del modelo de «salario familiar» masculino y del salario "de ayuda» o "complementario» femenino, ejerce una fuerte presión sobre el inmigrante varón. Partiendo de un imaginario social que legitima que el hombre no tenga que conciliar vida laboral y familiar, la dedicación exclusiva al trabajo remunerado y la falta de tiempo para la familia se agudiza en la sociedad receptora. Los bajos salarios y la vulnerabilidad jurídica y laboral - muchas veces trabajan sin contrato, expuestos a toda clase de exigencias por parte de los empleadores - se traduce en larguísimas jornadas laborales, a menudo sábados y domingos incluidos, lo que les deja escaso tiempo para ocuparse de sus hijos y no permite avanzar hacia la corresponsabilidad masculina en la esfera doméstico-familiar.

\section{Bibliografía}

Alicea, M. (1999). “"A Chambered Nautilus”. The Contradictory Nature of Puerto Rican Women's Role in the Social Construction of a Transnational Community». Gender and Society, vol. II, no 5, p. 597-626.

AlONSO, A. (1996). «El grupo de discusión en su práctica: memoria social, intertextualidad y acción comunicativa». Revista Internacional de Sociología, no 13, p. 5-36.

BALBO, L. (1978). «La doppia presenza». Inchiesta, núm. 32, p. 3-6.

BEM, S. (1981). "Gender schema theory: A cognitive account of sex typing». Psichological Review, núm. 88 (4), p. 354-364.

Borderías, C.; CARRASCO, C.; AlemanY, C. (1994). Las mujeres y el trabajo: rupturas conceptuales. Barcelona: Icaria-Fuhem.

BRULLET, C. (2000). «El debat sobre la conciliació ocupació-família dins el marc de la Unió Europea». Revista Catalana de Sociologia, no 12, p. 155-186.

BRUllet, C.; PARELla, S. (2005). «La conciliación de la vida familiar y laboral de las madres latinoamericanas. Una primera exploración al caso de la ciudad de Barcelona». En: FLAQUER, L.; SOLÉ, C. (eds.). El uso de las políticas sociales por las mujeres inmigrantes. Madrid: Instituto de la Mujer.

CARRASCO, C. y otros (2003). Tiempos, trabajos y flexibilidad: una cuestión de género, Madrid: IMU.

CARRASQUER, P. (2005). «En torno a la conciliación entre vida laboral y familiar. Una aproximación desde la perspectiva de la doble presencia». REDSI. Revista Especializada en Formación y Empleo de los Colectivos en Riesgo de Exclusión, no 6. Consultado en: <http://redsirevista.cebs-es.org $>$. 
Chinchilla, N.; Poelmans, S. (2004). La conciliació de la vida laboral, familiar $i$ personal. Barcelona: Pla Estratègic Metropolità de Barcelona.

Colectivo IoÉ (2001). Mujer, inmigración y trabajo. Madrid: Ministerio de Trabajo y Asuntos Sociales. Colección Observatorio Permanente de la Inmigración.

Garrido, L.; Gil CALVO, E. (1993). «El concepto de estrategias familiares». En: GARRRIDO, L.; GIL CALVO, E. (eds.). Estrategias familiares. Madrid: Alianza Editorial.

Gracia, F.; GonZÁlez, P.; Peiró, J. (1996). «El trabajo en relación con otros ámbitos de la vida». En: PeIró, J. (ed.). Tratado de Psicología del

Greenhaus, J.; Beutell, N. (1985). «Sources of conflict between work and family roles». Academy of Management Review, no 10, p. 76-88.

MARTínEZ, C. y otros (2002). «Antecedentes del conflicto interrol y su relación con el autoesquema de género». Anales de Psicología, no 18(2), p. 305-317.

PAṔ, N. (2005). «La conciliación de la vida laboral y familiar como proyecto de calidad de vida desde la igualdad». Revista Española de Sociología, no 5, p. 91-107.

PARELLA, S. (2003). Mujer, inmigrante y trabajadora: la triple discriminación. Barcelona: Anthropos.

Pedone, C. (2006). De l'Equador a Catalunya: El paper de la familia i les xarxes migratòries. Barcelona: Fundació Jaume Bofill.

PESSAR, P. (1984). «The linkage between the Household and Workplace of Dominican Women in the U.S.». International Migration Review, no 18 (4), p. 1188-1210.

SALTZMAN, J. (1992). Equidad y género. Madrid: Cátedra.

Tовío, C. (2001). «La familia y el empleo: prácticas y discursos de las mujeres». En: Radl Philipp, R. (ed.). Cuestiones actuales de Sociología del Género. Madrid: CIS.

Torns, T. (2004). «De la imposible conciliación a los permanentes malos arreglos». Ponencia presentada en el VIII Congreso Español de Sociología, organizado por la FES, del 23 al 25 de septiembre de 2004.

ToRnS, T., CARRASQUER, P. (1987). «Entorn dels conceptes de dona i treball». En: VV.AA. Visió de Catalunya. Barcelona: Diputació de Barcelona.

- (1999). "El perquè de la reproducció». PAPERS. Revista de Sociologia, no 59, p. 99-108. 